\title{
Radiographic Detection of the Relationship between Tonsilloliths and Dental Plaque-Related Pathologies in a Series of Digital Panoramic Radiographs
}

\author{
Ezgi Gurbuz ${ }^{a}$ Mujgan Gungor ${ }^{b}$ Hasan Hatipogluc \\ aDepartment of Periodontology, Faculty of Dentistry, Kutahya Health Sciences University, Kutahya, Turkey; \\ ${ }^{b}$ Department of Oral and Maxillofacial Radiology, Faculty of Dentistry, Kutahya Health Sciences University, Kutahya, \\ Turkey; ' Department of Periodontology, Faculty of Dentistry, Kutahya Health Sciences University, Kutahya, Turkey
}

\section{Highlights of the Study}

- This study aimed to investigate the relationship between tonsilloliths and dental plaque-related pathologies by radiographic examination.

- The number of the missing teeth and periodontal bone loss level was significantly associated with the presence of tonsilloliths.

- The significant results of this retrospective study should be confirmed by clinical trials conducted in a multidisciplinary manner.

\section{Keywords}

Tonsilloliths · Dental plaque · Decayed tooth · Apical periodontitis · Periodontal bone loss

\begin{abstract}
Objective: The purpose of this study was to analyse the prevalence of tonsilloliths and to determine radiographically whether there is a relationship between tonsilloliths and dental plaque-related pathologies in a series of digital panoramic radiographs. Materials and Methods: This retrospective study included digital panoramic radiographs of 859 patients admitted for routine dental examination. The panoramic images were examined for both the presence of tonsilloliths and the number of decayed, missing, restored
\end{abstract}

karger@karger.com www.karger.com/mpp

Karger $\stackrel{\text { ' }}{5}$
(C) 2021 The Author(s)

Published by S. Karger AG, Basel

This is an Open Access article licensed under the Creative Common Attribution-NonCommercial-4.0 International License (CC BY-NC) (http://www.karger.com/Services/OpenAccessLicense), applicable to the online version of the article only. Usage and distribution for commercial purposes requires written permission. teeth and apical periodontitis. Periodontal bone loss was also measured in thirds of optimal bone height according to the root length and a percentage of bone loss was obtained for each panoramic radiograph evaluated. Results: Tonsilloliths were observed in 141 (16.4\%) of all individuals. While there was no significant difference regarding the number of decayed teeth and restored teeth between tonsillolith cases (TT) and cases without tonsillolith (TC), the number of missing teeth and apical periodontitis in $T \mathrm{~T}$ was significantly higher than TC ( $p$ : 0.004, p: 0.030, respectively). There was a significant difference between the groups in terms of the mean percentage of bone loss ( $p: 0.001 ; p<0.05)$. In addition, cases showing bone loss between one-third and two-thirds of the optimal bone height in the TT group (52.5\%) were significantly higher than those in TC (45.5\%) ( $p$ : 0.035; $p<0.05)$.
Correspondence to:

Ezgi Gurbuz, ezgi.dogan@ksbu.edu.tr 
Conclusion: The relationship between dental plaque-related pathologies and tonsilloliths observed in this retrospective study should be confirmed by computed tomography studies and randomized, prospective, clinical trials conducted in a multidisciplinary manner. @ 2021 The Author(s).

Published by S. Karger AG, Basel

\section{Introduction}

Tonsilloliths are dystrophic soft tissue calcifications formed in the crypts of primarily palatine tonsils [1]. The accumulation of desquamated epithelial cells and microorganisms in enlarged crypts, along with deposition of inorganic salts results in tonsillar calcifications. These calcifications most commonly occur in adults and the mean age of occurrence was found to be 46.4 years $[2,3]$. They may be single or multiple, unilateral, or bilateral and are usually small in size and asymptomatic. However, individuals with large ones may show symptoms of chronic sore throat, halitosis, tonsillitis, irritation, and discomfort.

Although the exact aetiology and pathogenesis of tonsilloliths are unknown, chronic tonsillar inflammation may trigger their development [4]. Desquamated epithelium, inflammatory exudate, and food debris serve as ideal media for the growth of bacteria, viruses, and fungi [5]. Cooper et al. [2] reported that Actinomyces is a common resident of an abnormal tonsil and forms a nidus for calcification. However, a recent study reported that while a strong association was identified between Actinomyces and tonsilloliths, this pathological calcification is not based on solely one microorganism because of its polymicrobial nature [6]. A limited number of studies, investigating the bacterial composition of tonsilloliths, focused on heterogeneous microbial composition [7,8]. Tonsilloliths, as living polymicrobial biofilms, were shown to include Streptococcus, Lactobacillus, Actinomyces, Eubacterium, Fusobacterium, Megasphaera, Porphyromonas, Prevotella, Selenomonas and Tannerella species, all of which appear to be associated with dental biofilms.

Tonsilloliths are mostly asymptomatic, incidentally found during a routine dental examination. In this context, a panoramic radiograph is a valuable diagnostic tool for the assessment of soft tissue calcifications, considering the broad anatomical view, low cost, and low radiation dose of this imaging modality. On a panoramic radiograph, palatine tonsilloliths may appear as multiple, poorly defined small radiopaque masses superimposed

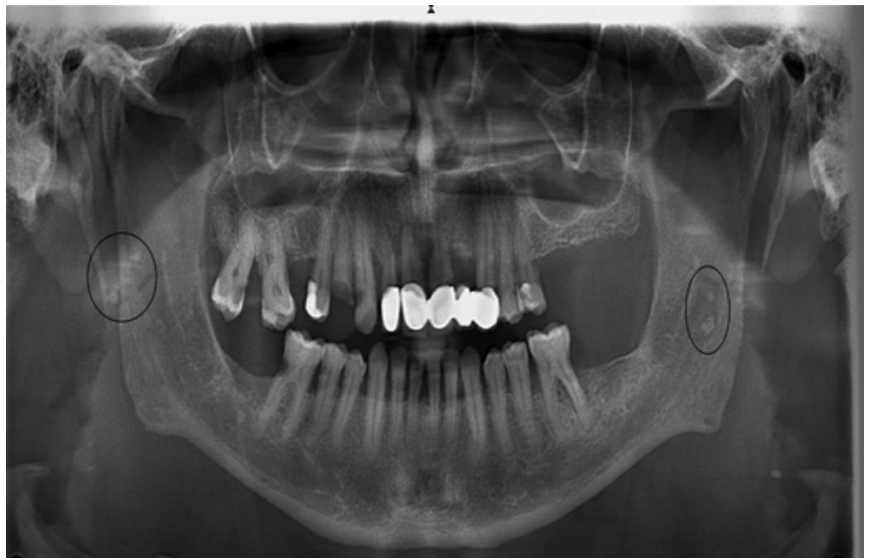

Fig. 1. Representative image of tonsilloliths superimposed on the mandibular ramus and surrounding soft tissue.

on the ramus of the mandible and surrounding soft tissue [9]. Several recent studies, assessing the prevalence of tonsilloliths on panoramic radiographs, reported a wide range of $0.74-13.4 \%$ [9-13].

Considering the similarities between dental biofilm and tonsilloliths, this retrospective study aimed to investigate the prevalence of tonsilloliths and to ascertain radiographically whether there is a relationship between tonsilloliths and dental plaque-related pathologies (e.g., dental caries, apical periodontitis, and periodontal disease) in a series of digital panoramic radiographs.

\section{Materials and Methods}

The study protocol was prepared according to the Declaration of Helsinki $[14,15]$ and it was approved by the Ethics Committee of Kutahya Health Sciences University (Decision Number: 2019/03). This retrospective study included digital panoramic radiographs of patients attending the Department of Maxillofacial Radiology, Faculty of Dentistry, Kutahya Health Sciences University between November 2018 and October 2019 for routine dental examination. Patients under 18 years, those with a history of surgery and trauma, and low-quality radiographs were excluded. The study sample was composed of 859 digital panoramic radiographs (495 [57.6\%] were female patients and 364 [42.4\%] were male). The average age was $43.42 \pm 13.06$ years.

\section{Radiographic Analysis}

Panoramic radiographs were acquired using a Veraviewepocs panoramic X-ray device (Morita, Kyoto, Japan). The device parameters were set at $8.9 \mathrm{~mA}$ and $64 \mathrm{kVp}$, with an exposure time of $7.4 \mathrm{~s}$. Panoramic images were stored on a desktop computer and all radiographical evaluations were made under standardized conditions (darkened room, without any daylight) by one investigator (E.G.). 
Table 1. Minimum, maximum, mean, standard deviation, and median values of study parameters

\begin{tabular}{lllll}
\hline & Minimum & Maximum & Mean \pm SD & Median \\
\hline Decayed tooth, $n$ & 0 & 14 & $1.59 \pm 1.76$ & 1 \\
Missing tooth, $n$ & 0 & 32 & $7.15 \pm 6.34$ & 5 \\
Restored tooth, $n$ & 0 & 22 & $6.41 \pm 4.60$ & 6 \\
Apical periodontitis, $n$ & 0 & 11 & $1.19 \pm 1.36$ & 1 \\
Periodontal bone loss, $\%$ & 0 & 0.98 & $0.34 \pm 0.17$ & 0.33 \\
\hline
\end{tabular}

Table 2. The number of decayed, missing, restored teeth, and apical periodontitis and the percentage of periodontal bone loss regarding the presence of tonsilloliths

\begin{tabular}{llllllll}
\hline & \multicolumn{1}{l}{ TT } & & & TC & & $p$ value \\
& min-max & mean \pm SD (median) & & min-max & mean \pm SD (median) & \\
\hline Decayed tooth, $n$ & $0-8$ & $1.75 \pm 1.77(1)$ & & $0-14$ & $1.55 \pm 1.75(1)$ & 0.170 \\
Missing tooth, $n$ & $0-32$ & $8.45 \pm 6.74(7)$ & & $0-32$ & $6.89 \pm 6.23(5)$ & $0.004^{*}$ \\
Restored tooth, $n$ & $0-19$ & $6.55 \pm 4.79(6)$ & & $0-22$ & $6.38 \pm 4.56(6)$ & 0.845 \\
Apical periodontitis, $n$ & $0-6$ & $1.36 \pm 1.31(1)$ & & $0-11$ & $1.16 \pm 1.37(1)$ & $0.030^{*}$ \\
Periodontal bone loss, \% & $0-0.88$ & $0.39 \pm 0.17(0.37)$ & & $0-0.98$ & $0.34 \pm 0.18(0.33)$ & $0.001^{*}$
\end{tabular}

Mann-Whitney U test. * $p<0.05$.

The images were examined for the presence of tonsilloliths. Single or multiple radiopacities superimposed on the mandibular ramus and surrounding soft tissue were defined as tonsilloliths (Fig. 1). The location, number, and shape were considered in the differential diagnosis with other soft tissue calcifications such as ossification of stylohyoid ligament, carotid artery calcifications, sialoliths, and calcified lymph nodes [16]. The images were also examined for radiographic evidence of decayed, missing and restored tooth, apical periodontitis, and periodontal bone loss. Periodontal bone loss was evaluated according to Dias et al. [17]. Bone loss was considered when the alveolar crest was found to be $2 \mathrm{~mm}$ or more from the cementoenamel junction and measured in thirds of optimal bone height according to the root length. The average of the evaluations of all teeth presenting bone loss was converted to a percentage and the percentage of bone loss was obtained for each panoramic radiograph evaluated. Percentage $<0.33$ was considered as bone loss less than one-third of the optimal bone height, $0.33 \leq x$ $\leq 0.67$ as a bone loss between one-third and two-thirds, and the percentage of more than 0.67 as bone loss more than two-thirds.

\section{Statistical Analysis}

Data obtained in the study were evaluated using the IBM SPSS Statistics 22 (IBM Corp., Armonk, NY, USA) programme. The distribution of parameters was analysed by Kolmogorov-Smirnov and Shapiro Wilk tests, and it was found that the parameters did not show a normal distribution. The study data were evaluated primarily by descriptive statistical methods (minimum, maximum, mean, standard deviation, median, frequency). MannWhitney $U$ test and $\chi^{2}$ test were used to compare quantitative and qualitative data, respectively. The significance level was set at $p<$ 0.05 .

The Relationship between Tonsilloliths and Dental Plaque-Related Pathologies

\section{Results}

On digital panoramic images, of the 859 individuals, $141(16.4 \%)$ were found to have radiopaque lesions that were identified as tonsilloliths. Of these subjects participating in the study, 77 were men and 64 were women, and the prevalence of tonsilloliths was $21.2 \%$ and $12.9 \%$, respectively. Males presented significantly higher prevalence than females $(p: 0.001 ; p<0.05)$. The mean age of pooled tonsillolith cases (TT) $(47.13 \pm 13.12)$ was significantly greater than cases without tonsillolith (TC) (42.69 $\pm 12.93)(p: 0.000 ; p<0.05)$.

Forty-nine cases of tonsilloliths (34.8\%) were located on the right side, 37 cases on the left side (26.2\%), and 55 cases were bilateral (39\%). There was no significant difference in terms of the uni- or bilaterality of tonsilloliths ( $p$ : 0.167$)$.

Table 1 summarizes the minimum, maximum, mean, standard deviation and median values of radiographically detected decayed, missing, restored tooth, apical periodontitis, and also periodontal bone loss. Of the 859 individuals, 435 (50.6\%) were found to have bone loss less than one-third of the optimal bone height, 401 (46.7\%) had bone loss between one-third and two-thirds, and 23 (2.7\%) had bone loss more than two-thirds.

The results of the Mann-Whitney $U$ test are displayed in Table 2. While there was no significant difference in 
Table 3. Periodontal bone loss level according to the presence of tonsilloliths

\begin{tabular}{|c|c|c|c|c|c|}
\hline \multirow[t]{2}{*}{ Periodontal bone loss } & \multicolumn{2}{|l|}{$\mathrm{TT}$} & \multicolumn{2}{|l|}{$\mathrm{TC}$} & \multirow[t]{2}{*}{$p$ value } \\
\hline & $n$ & $\%$ & $n$ & $\%$ & \\
\hline Less than one-third of the optimal bone height & 60 & 42.6 & 375 & 52.2 & \\
\hline Between one-third and two-thirds of the optimal bone height & 74 & 52.5 & 327 & 45.5 & $0.035^{*}$ \\
\hline More than two-thirds of the optimal bone height & 7 & 5.0 & 16 & 2.2 & \\
\hline
\end{tabular}

$\mathrm{X}^{2}$ test. ${ }^{*} p<0.05$

Fig. 2. Graph demonstrating the relationship between the presence of tonsilloliths and periodontal bone loss level.

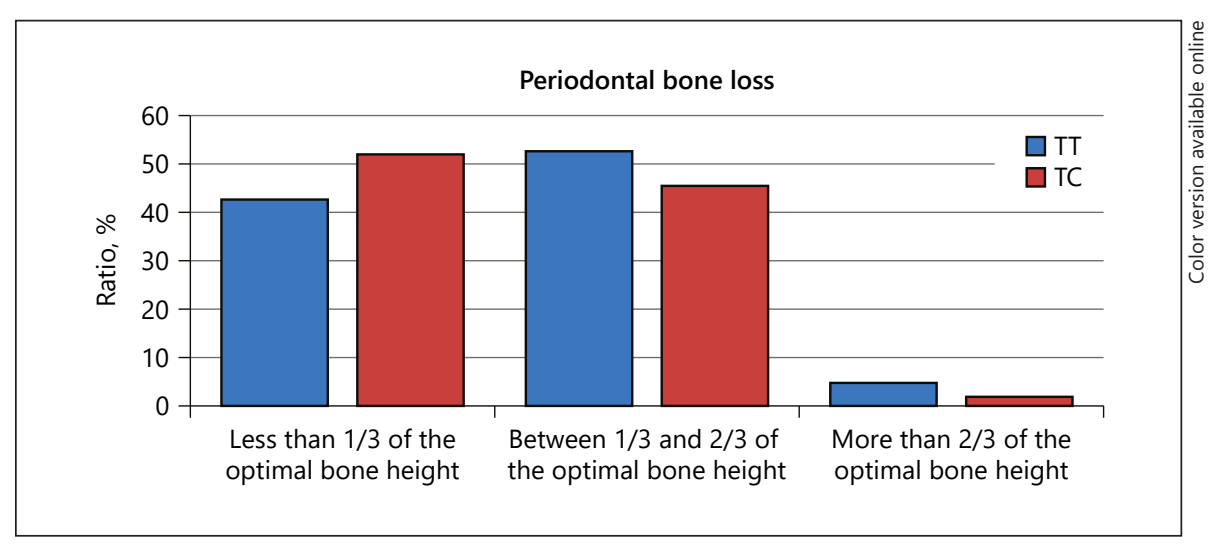

terms of the number of decayed teeth and restored teeth between TT and TC, the number of missing teeth and apical periodontitis in TT was significantly higher than TC ( $p: 0.004, p: 0.030$, respectively). In addition, the mean percentage of bone loss in TT was significantly higher than TC ( $p$ : $0.001 ; p<0.05)$. There was a statistically significant relationship between the presence of tonsillolith and the percentage of periodontal bone loss.

According to the results of the $\chi^{2}$ test, cases showing bone loss between one-third and two-thirds of the optimal bone height in the TT group (52.5\%) were significantly higher than those in TC $(45.5 \%)(p: 0.035 ; p<0.05)$ (Table 3) (Fig. 2). When the evaluations were performed in the age groups (18-40 years, $40-60$ years, $>60$ years) according to the presence of tonsilloliths, no difference was observed in terms of plaque-related pathologies in the groups $(p>0.05)$ (Table 4$)$.

\section{Discussion}

Panoramic radiography, one of the radiographic examinations most used by dentists, is an important tool for the detection of pathological calcifications such as tonsil- loliths. We observed tonsilloliths in $16.4 \%$ of digital panoramic radiographs in the study population. The prevalence rate is similar to the tonsillolith detection rate (18.5\%) reported by Ozdede et al. [18]. However, several studies reported lower prevalence rates $(7.2 \%, 7.3 \%$, $8.14 \%$, respectively) on panoramic radiographs $[11,19$, 20]. This discrepancy may be attributed to the racial differences, sample size, variations in the panoramic equipment, imaging modality (analogue vs. digital) and the angulation of the X-ray projection.

We observed that the mean age of the TT group was significantly higher than TC. This result may be associated with the frequent occurrence of chronic tonsillar inflammation in older adults because of the risk factors like smoking and poor oral hygiene [21,22]. Oral bacteria in secretions in contact with tonsillar epithelium may adhere to the mucosal surface and may stimulate cytokine production by mucosal epithelium [23]. This mechanism, along with poor oral hygiene, may increase susceptibility to tonsillar infection. According to a clinical study, it was shown that the prevalence of the periodontal disease is increased in patients with peritonsillar abscess [24]. Likewise, bacteriologic data demonstrated a relationship between tonsillitis and pericoronitis [25]. The aforemen- 
Table 4. Evaluations according to the presence of tonsilloliths in the age groups

\begin{tabular}{|c|c|c|c|c|c|}
\hline & \multicolumn{2}{|l|}{$\pi$} & \multicolumn{2}{|l|}{$\mathrm{TC}$} & \multirow[t]{2}{*}{$p$ value } \\
\hline & $\min -\max$ & mean \pm SD (median) & $\min -\max$ & mean \pm SD (median) & \\
\hline \multicolumn{6}{|l|}{$18-40$ years } \\
\hline Decayed tooth, $n$ & $0-8$ & $2.2 \pm 1.84(2)$ & $0-9$ & $1.71 \pm 1.68(1)$ & 0.073 \\
\hline Missing tooth, $n$ & $0-23$ & $4.45 \pm 4.47(3)$ & $0-21$ & $3.54 \pm 3.09(3)$ & 0.358 \\
\hline Restored tooth, $n$ & $0-18$ & $5.93 \pm 4.98(5)$ & $0-20$ & $5.79 \pm 4.21(5)$ & 0.850 \\
\hline Apical periodontitis, $n$ & $0-3$ & $1.07 \pm 1.13(1)$ & $0-11$ & $1.12 \pm 1.36(1)$ & 0.942 \\
\hline Periodontal bone loss, \% & $0-0.66$ & $0.29 \pm 0.2(0.3)$ & $0-0.98$ & $0.25 \pm 0.19(0.3)$ & 0.122 \\
\hline \multicolumn{6}{|l|}{$40-60$ years } \\
\hline Decayed tooth, $n$ & $0-7$ & $1.53 \pm 1.71(1)$ & $0-10$ & $1.5 \pm 1.77(1)$ & 0.714 \\
\hline Missing tooth, $n$ & $2-26$ & $9 \pm 5.58(8)$ & $0-32$ & $8.64 \pm 6.05(7)$ & 0.476 \\
\hline Restored tooth, $n$ & 0-19 & $6.72 \pm 4.67(6)$ & $0-22$ & $6.8 \pm 4.69(6)$ & 0.872 \\
\hline Apical periodontitis, $n$ & $0-6$ & $1.49 \pm 1.41(1)$ & $0-9$ & $1.23 \pm 1.43(1)$ & 0.067 \\
\hline Periodontal bone loss, \% & $0.33-0.88$ & $0.45 \pm 0.14(0.4)$ & $0-0.81$ & $0.4 \pm 0.12(0.4)$ & 0.103 \\
\hline \multicolumn{6}{|l|}{$>60$ years } \\
\hline Decayed tooth, $n$ & $0-6$ & $1.59 \pm 1.76(1)$ & $0-14$ & $1.03 \pm 1.94(1)$ & 0.130 \\
\hline Missing tooth, $n$ & $4-32$ & $14.59 \pm 8.81(13.5)$ & $3-32$ & $14.98 \pm 8.14(12.5)$ & 0.753 \\
\hline Restored tooth, $n$ & $0-18$ & $7.23 \pm 4.91(6)$ & $0-20$ & $7.25 \pm 5.3(6)$ & 0.987 \\
\hline Apical periodontitis, $n$ & $0-4$ & $1.5 \pm 1.26(1)$ & $0-4$ & $0.95 \pm 1.05(1)$ & 0.057 \\
\hline Periodontal bone loss, \% & $0-0.6$ & $0.41 \pm 0.12(0.4)$ & $0-0.87$ & $0.44 \pm 0.16(0.4)$ & 0.966 \\
\hline
\end{tabular}

tioned studies emphasized the possibility of a causal relationship for these pathologies.

Although small tonsilloliths are mostly asymptomatic, large ones were shown to cause symptoms such as chronic sore throat, tonsillitis, and halitosis $[3,4]$. As one of the non-oral reasons for halitosis, this soft tissue calcification was shown to represent a tenfold increased risk for halitosis [26]. Analysis of bacterial composition of tonsilloliths revealed that these calcifications share the same volatile sulphur compound-producing bacteria (e.g., Porphyromonas, Prevotella, Fusobacterium, Tannerella), as the origin of halitosis, with the tongue and periodontal pocket [7]. The tonsilloliths were also found morphologically similar to dental biofilm and shown to consist of various bacteria including Fusobacterium nucleatum and Streptococcus sangius [8]. Similar biofilm colonization is not coincidental in anatomically close regions like the oral cavity and upper respiratory tract.

Considering these similarities and the related causality, it was assumed that the prevalence of tonsilloliths may be associated with the prevalence of dental plaque-related pathologies such as periodontal disease, apical periodontitis, and caries. This study is first radiological study to investigate the relationship between tonsilloliths and dental plaque-related pathologies in terms of reviewing the relevant literature. According to the results of this

The Relationship between Tonsilloliths and Dental Plaque-Related Pathologies study, a significant relationship was found between the presence of tonsilloliths and periodontal bone loss level ( $p: 0.035 ; p<0.05$ ). In addition, the number of missing teeth and apical periodontitis was found to be significantly higher in TT ( $p$ : 0.004, $p: 0.030$, respectively). Although it was not statistically significant, the number of decayed teeth and restored teeth was higher in TT ( $p$ : 0.170, $p$ : 0.845 , respectively). In the light of these data, it can be speculated that for the prevention of tonsillolith formation in susceptible patients, dental practices such as periodontal, endodontic, and restorative treatment may be suggested as they are more advantageous than treatment options for tonsillolith (e.g., tonsillectomy, repeated antibiotic usage) in terms of invasiveness and antibiotic resistance. Thus, the microorganism burden in dental biofilm, which is thought to play a role in the etiopathogenesis of tonsilloliths, can be reduced. However, to draw this conclusion, besides radiological evaluation, in a clinical setting, studies evaluating dental problems of patients exhibiting tonsilloliths are needed. It seems appropriate therefore to conduct multidisciplinary studies, for example, with otolaryngologists.

In addition, the possible relationship between tonsillolith and dental plaque-related pathologies should suggest that halitosis, which does not improve despite restorative and periodontal treatment, may be caused by tonsil- 
loliths and hence the patient may need to be referred for otolaryngology consultation. Considering the effect of halitosis on quality of life, it is important for the dentist to be able to recognize the radiopacities that indicate the presence of tonsilloliths in the panoramic radiograph, which is a routine radiographic procedure.

This study has several limitations. Panoramic radiography creates inherent limitations such as superimposition of various structures, distortion, and magnification in the interpretation of tonsilloliths. Also, ghost images may lead to misdiagnosis [3]. However, for a routine dental examination, the central role of this radiological technique has not yet been displaced by the availability of three-dimensional techniques [13]. Moreover, using digital panoramic radiography, image quality can be improved by adjustment of image brightness and contrast [27].

Although panoramic radiography is used more frequently than computed tomography (CT) for a routine examination, CT scans have been found to have higher tonsillolith detection rates than panoramic radiographs $[9,18,19,28]$. Therefore, it may be more accurate to associate the prevalence of tonsilloliths with dental plaquerelated pathologies using CT scans.

Periodontal bone loss, measured from a panoramic radiograph, is not indicative of the current clinical situation. For example, clinical indexes (like plaque index and gingival index) taken from patients could not be evaluated. However, it was shown that there is a close relationship between the clinical periodontal index scores and the bone loss measured from the panoramic radiograph [29]. The result indicating more tooth and periodontal bone loss in older adults with tonsilloliths should be interpreted with caution. As tooth and periodontal bone loss are ageing-related problems, this result may be a coincidence. Lacking a history of periodontal disease, tonsillitis, or any other tonsillar problem as a result of the retrospective design of the study is another limitation. This issue should be considered in future studies.

\section{Conclusion}

Tooth loss, periodontal bone loss, and formation of tonsilloliths may be confounding factors in the ageing population. Therefore, the relationship between dental plaque-related pathologies and tonsilloliths, observed in this retrospective study, should be confirmed by CT studies and randomized, prospective, clinical trials conducted in a multidisciplinary manner. The prevention or early diagnosis of tonsilloliths may be possible, especially for patients with a predisposition of periodontal disease or tooth loss. Moreover, clinicians should suspect the presence of tonsillolith in the case of unimproved halitosis despite dental treatments.

\section{Statement of Ethics}

Ethics approval was received from the Ethics Committee of Kutahya Health Sciences University (Decision Number: 2019/03).

\section{Conflict of Interest Statement}

The authors have no conflicts of interest to declare.

\section{Funding Sources}

No funding was obtained for this study.

\section{Author Contributions}

The followings are the authors' contributions: Ezgi Gurbuz: investigation and writing; Mujgan Gungor: methodology and resources; Hasan Hatipoglu: conceptualization and supervision.

\section{Data Availability Statement}

The data that support the findings of this study are not publicly available due to the information that could compromise the privacy of the research material but are available from E.G. upon reasonable request.

\section{References}

1 Mandel L. Multiple bilateral tonsilloliths: case report. J Oral Maxillofac Surg. 2008 Jan;66: 148-50.

2 Cooper MM, Steinberg JJ, Lastra M, Antopol S. Tonsillar calculi: report of a case and review of the literature. Oral Surg Oral Med Oral Pathol. 1983 Mar;55:239-43.

3 Ram S, Siar CH, Ismail SM, Prepageran N. Pseudo bilateral tonsilloliths: a case report and review of the literature. Oral Surg Oral Med Oral Pathol Oral Radiol Endod. 2004 Jul; 98:110-4.

4 Lo RH, Chang KP, Chu ST. Upper airway obstruction caused by bilateral giant tonsilloliths. J Chin Med Assoc. 2011 Jul;74:329-31.

5 Weller CV. II. The incidence and pathogenesis of tonsillar concretions. Ann Otol Rhinol Laryngol. 1924 Mar;33(1):79-127.
6 Arvisais-Anhalt S, Quinn A, Bishop JA, Wang CS, Mitchell RB, Johnson RF, et al. Palatine tonsilloliths and Actinomyces: a multi-institutional study of adult patients undergoing tonsillectomy. Otolaryngol Head Neck Surg. 2020 Oct;163:743-9.

7 Tsuneishi M, Yamamoto T, Kokeguchi S, Tamaki N, Fukui K, Watanabe T. Composition of the bacterial flora in tonsilloliths. Microbes Infect. 2006 Aug;8:2384-9. 
8 Stoodley P, Debeer D, Longwell M, Nistico L, Hall-Stoodley L, Wenig B, et al. Tonsillolith: not just a stone but a living biofilm. Otolaryngol Head Neck Surg. 2009 Sep;141:316-21.

9 Takahashi A, Sugawara C, Kudoh T, Ohe G, Takamaru N, Tamatani T, et al. Prevalence and imaging characteristics of palatine tonsilloliths evaluated on 2244 pairs of panoramic radiographs and CT images. Clin Oral Investig. 2017 Jan;21:85-91.

10 Sutter W, Berger S, Meier M, Kropp A, Kielbassa AM, Turhani D. Cross-sectional study on the prevalence of carotid artery calcifications, tonsilloliths, calcified submandibular lymph nodes, sialoliths of the submandibular gland, and idiopathic osteosclerosis using digital panoramic radiography in a Lower Austrian subpopulation. Quintessence Int. 2018 Mar;49:231-42.

11 Aoun G, Nasseh I, Diab HA, Bacho R. Palatine tonsilloliths: a retrospective study on 500 digital panoramic radiographs. J Contemp Dent Pract. 2018 Oct;19:1284-7.

12 Ghassemzadeh S, Sbricoli L, Frigo AC, Bacci C. Incidental findings detected with panoramic radiography: prevalence calculated on a sample of 2017 cases treated at a major Italian trauma and cancer centre. Oral Radiol. 2021;37(3):507-17.

13 MacDonald D, Yu W. Incidental findings in a consecutive series of digital panoramic radiographs. Imaging Sci Dent. 2020 Mar;50:5364.

14 Rickham PP. Human experimentation. Code of ethics of the World Medical Association. Declaration of Helsinki. Br Med J. 1964 Jul; 2(5402): 177 .
15 Palacios R. Post-trial access and the new version of the Declaration of Helsinki. Colomb Med. 2013 Dec;44:206-7.

16 Monsour PA, Romaniuk K, Hutchings RD. Soft tissue calcifications in the differential diagnosis of opacities superimposed over the mandible by dental panoramic radiography. Aust Dent J. 1991 Apr;36:94-101.

17 Dias MJ, Franco A, Junqueira JL, Fayad FT, Pereira PH, Oenning AC. Marginal bone loss in the second molar related to impacted mandibular third molars: comparison between panoramic images and cone beam computed tomography. Med Oral Patol Oral Cir Bucal. 2020 May;25:e395-402.

18 Ozdede M, Akay G, Karadag O, Peker I. Comparison of panoramic radiography and conebeam computed tomography for the detection of tonsilloliths. Med Princ Pract. 2020 Jun;29:279-84.

19 Oda M, Kito S, Tanaka T, Nishida I, Awano S, Fujita Y, et al. Prevalence and imaging characteristics of detectable tonsilloliths on 482 pairs of consecutive $\mathrm{CT}$ and panoramic radiographs. BMC Oral Health. 2013;13:54.

20 Bamgbose BO, Ruprecht A, Hellstein J, Timmons S, Qian F. The prevalence of tonsilloliths and other soft tissue calcifications in patients attending oral and maxillofacial radiology clinic of the University of Iowa. ISRN Dent. 2014;2014:839635.

21 Cinamon U, Goldfarb A, Marom T. The impact of tobacco smoking upon chronic/recurrent tonsillitis and post tonsillectomy bleeding. Int Arch Otorhinolaryngol. 2017 Apr;21:165-70.
22 Adetayo A, Akinola M, Oladeji M, Oyedele T, Adetayo $\mathrm{M}$, Ladele $\mathrm{A}$. Is there any association between oral hygiene and the development of tonsillitis or tonsillar hyperplasia. Int J Med Sci Clin Invent. 2020 Apr;7(4):4781-7.

23 Scannapieco FA. Role of oral bacteria in respiratory infection. J Periodontol. 1999 Jul;70: 793-802.

24 Georgalas C, Kanagalingam J, Zainal A, Ahmed H, Singh A, Patel KS. The association between periodontal disease and peritonsillar infection: a prospective study. Otolaryngol Head Neck Surg. 2002 Jan;126:91-4.

25 Rajasuo A, Jousimies-Somer H, Savolainen S, Leppänen J, Murtomaa H, Meurman JH. Bacteriologic findings in tonsillitis and pericoronitis. Clin Infect Dis. 1996 Jul;23:51-60.

26 Dal Rio A, Franchi-Teixeira A, Nicola E. Relationship between the presence of tonsilloliths and halitosis in patients with chronic caseous tonsillitis. Br Dent J. 2008 Jan;204:1-4.

27 Moreira-Souza L, Michels M, Lagos de Melo LP, Oliveira ML, Asprino L, Freitas DQ. Brightness and contrast adjustments influence the radiographic detection of soft tissue calcification. Oral Dis. 2019 Oct;25:1809-14.

28 Yamashita K, Oda M, Tanaka T, Nishida I, Wakasugi-Sato N, Matsumoto-Takeda S, et al. Changes in tonsillolith characteristics detected in a follow-up CT study. BMC Oral Health. 2021 Feb;21:72.

29 Walsh TF, al-Hokail OS, Fosam EB. The relationship of bone loss observed on panoramic radiographs with clinical periodontal screening. J Clin Periodontol. 1997 Mar;24:153-7.
The Relationship between Tonsilloliths and Dental Plaque-Related Pathologies
Med Princ Pract 2022;31:149-155

DOI: $10.1159 / 000521687$ 